eye of a navigator can accurately assess the risk of collision or the need to mancuvre. He must, therefore, depend upon instrumental information for making his decisions; in other words, in clear weather as in thick, he must use his radar and plot continuously if he is not to hazard his ship. If the argument is put forward that this will require two men on watch together and that the state of manning does not permit this to be done, the answer is that a change in organization must be made to make it possible.

\title{
Watch Keeping at Sea
}

\author{
from Captain P. A. Thompson
}

THE two following incidents might be of interest as an example of situations which arise today, and which well illustrate the standard of seamanship and watchkeeping which are encountered.

On Wednesday, 28 October, at 1700 hours, zone time, and in broad daylight with clear weather, we were proceeding in ballast on a course of $024^{\circ}$ in the southern part of the Moçambique Channel when we had to take avoiding action because of a bulk/ore carrier of about 50,000 tons deadweight which was approaching our port side on a steady bearing, on a course of approximately $070^{\circ}$. The vessel was [name provided] of Liberian register and believed to be of Greek ownership, and passed blithely on its way. No sign of any watchkeeper could be seen on the bridge. It is, of course, quite possible that at this time he had gone below for his evening meal; such habits are apparently not unknown.

On Sunday, i 5 November, at 1030 hours, zone time (G.M.T. + 3 hr.) in Lat. $3^{\circ} \mathrm{S}$. and Long $47^{\circ} \mathrm{E}$. on a course of $207^{\circ}$, when a Japanese cargo ship of about I 2,000 tons deadweight on a course of about $260^{\circ}$, in perfectly clear weather, approached from our port side and passed ahead of us at a distance of a little less than one mile. Although we were not called upon to take action in this case, had the other vessel had an engine breakdown or steering failure whilst still on our port bow it is doubtful if she could have kept clear. It is also debatable whether we could have taken avoiding action in sufficient time to avoid collision, bearing in mind that the distance of advance of a vessel of this size, 209,000 tons deadweight, when turning at full speed and under full rudder is of the order of 3 to $3 \frac{1}{2}$ cables.

It is this type of carelessness and indifference that rules are of little use against, and against which one must be constantly on guard. People who will act in this manner in clear weather are equally capable of being just as irresponsible and proceeding at full speed in fog, with complete disregard for the safety of both themselves and others. 